\title{
perifèria
}

Número 11, Diciembre 2009

www.periferia.name

\section{Comercio justo, Estado y sociedad civil. Una aproximación crítica.}

Susana R. Presta - FFyL, Universidad de Buenos Aires- CONICET

\section{Resumen}

En el presente artículo, nos proponemos analizar el caso de una cadena productiva textil, enmarcada en el comercio justo, la misma se desarrolla en la localidad de Capilla del Monte, Córdoba, Argentina. Dicho emprendimiento aglutina un importante número de trabajadoras y trabajadores en el marco de procesos de trabajo de carácter doméstico y artesanal. Amparado bajo los lineamientos del desarrollo económico local, la cadena productiva textil fue creada y financiada por organismos del Estado nacional. Es nuestro propósito dar cuenta de los discursos y prácticas que atraviesan al comercio justo, como así también, analizar las formas de construcción de subjetividad en el marco de las nuevas tecnologías de gobierno que aparecen en este ámbito.

Palabras clave: comercio justo, cadena productiva textil, desarrollo local.

\begin{abstract}
In this paper, we propose to analyze the case of a textile productive chain, framed in fair trade, it takes place in the town of Capilla del Monte, Cordoba, Argentina. This iniciative brings together a large number of workers in the context of domestic and handmade work processes. Under the guidelines of local economic development, the textile productive chain was created and financed by agencies of the national State. It is our purpose to account for the discourses and practices that cross over to fair trade as well, discuss ways of construction of subjectivity in the context of new technologies of government that appear in this context.
\end{abstract}

Keywords: fair trade, textile production chain, local development.

\section{I ntroducción}

La mutación socio-técnica que tiene lugar a partir de los '70 en la Argentina y en el mundo, mediante la constante expulsión y mayor precarización del trabajo, han generado respuestas orientadas a iniciativas sociales cuya propuesta radicó en posibles formas de reinserción en el mercado. Estas últimas, se estructuran sobre una organización socioeconómica basada en los principios de la economía social y solidaria. Por consiguiente, los deseos y aspiraciones de una clase trabajadora 


\section{perifèria}

Número 11, Diciembre 2009

\section{www.periferia.name}

cuyas capacidades de trabajo ya no eran requeridas formalmente por el sector empresarial, concentraba un potencial social que no tardaría en ser reincorporado en la agenda del Estado y el sector privado. Promulgando un discurso no consumista y contrario a la racionalidad instrumental del capitalismo, los sujetos que construyen estas iniciativas, paradójicamente, continúan vinculándose como consumidores en el mercado capitalista. En este sentido, las formas de reincorporación de estos sectores sociales permitirían, a su vez, garantizar la continuidad del mercado en tanto la economía social y solidaria mantiene su posición de consumidores, prescindiendo de una relación salarial. Esto último, implicaría asimismo un ahorro en la reproducción social de una fuerza de trabajo ajustada a los requerimientos de dichas iniciativas comunitarias y emprendimientos socio-productivos. La organización del Estado se ajustó a la lógica empresarial y su discurso, iniciando la supuesta "modernización" del mismo, para facilitar la implementación de las políticas de desarrollo económico previstas para la economía social y solidaria. Políticas que encierran una nueva forma de extender los intereses de los agentes del capital hacia todos los ámbitos de la sociedad. De este modo, las alianzas entre sectores se consolidaron y, pronto, aquello que había surgido como un posible foco de resistencias y conflictos fue resignificado en función de nuevas relaciones de poder.

En este sentido, nos interesa problematizar dichas transformaciones socioeconómicas y políticas, para lo cual hemos elegido realizar nuestra investigación sobre un caso empírico, a partir del cual podremos ahondar en la complejidad del tema abordado. Hemos realizado nuestro primer trabajo de campo durante el transcurso del corriente año, a partir de entrevistas semi-estructuradas y observaciones participantes. Si bien, la presente investigación se halla en una fase inicial, nuestro análisis se enmarca en lineamientos e interrogantes, resultado de investigaciones ya finalizadas ${ }^{1}$.

1 Véase Tesis de Doctorado "Paradojas de la economía social y solidaria en el marco de las transformaciones en los procesos de acumulación de capital." Facultad de Filosofía y Letras, UBA, 2009. Asimismo, se encuentran en curso investigaciones afines en el marco del proyecto "Economía Social y Solidaria en el ámbito rural-urbano. Políticas de Desarrollo y nuevas perspectivas de acumulación de 


\section{perifèria}

Número 11, Diciembre 2009

www.periferia.name

Desde el 2003, se encuentra en funcionamiento la Cadena de Valor Textil Artesanal, llevada a cabo en el Valle de Punilla, Córdoba (Argentina), en el marco de la experiencia asociativa "Una cuestión de manos y de palabras" implementada por el trabajo conjunto entre Unidades de Extensión del Instituto Nacional de Tecnología Industrial (INTI) y del Instituto Nacional de Tecnología Agropecuaria (INTA) Cruz del Eje, Córdoba. El objetivo de la experiencia consiste en articular la producción ovina con el hilado de la lana y la confección de prendas tejidas. Esta experiencia forma parte de las actividades de extensión del INTI en economía social y tiene como propósito ofrecer una fuente de trabajo a partir de una tarea artesanal y un oficio ancestral que abarca a 120 trabajadores, a partir del desarrollo económico local.

Se utilizan protocolos de hilados diseñados por el INTI, la fijación del "precio justo" para cada tipo de hilado y el uso de un protocolo de gestión con el fin de permitir la participación y articulación de trabajadores alejados geográficamente, lo cual otorga un "sentido de pertenencia a la cadena".

Las producciones artesanales de las hilanderas, ya que el $90 \%$ son mujeres adultas, se comercializan en ferias, boutiques de la región y por Internet. Según técnicos del $\mathrm{INTI}^{2}$, el objetivo al principio fue facilitar la organización social de unidades productivas de subsistencia en una cadena de valor para producir textiles artesanales (fibras textiles, hilados y ropa), imitando la figura de fábrica a cielo abierto, que apela a recuperar conductas de organización basadas en la solidaridad y la ayuda mutua, sin perder de vista la eficiencia de los resultados económicos. Asimismo, informan que el proyecto se puso en práctica en una zona poco industrializada y con pocas oportunidades de empleo. Por tal razón, la prioridad es "aliviar la pobreza", reconstituyendo una actividad arraigada como la textil, con

capital." Programa de Reconocimiento Institucional, Facultad de Filosofía y Letras, UBA. Directora: Dra. Susana R. Presta. Co-directora: Lic. Liliana S. Landaburu. Período: 2008-2010.

2 Artículo "Perfiles de las mujeres que hilaron su historia", Diario La Nación, sábado 26 de agosto de 2006, Sección Economía Social. 


\section{perifèria}

Número 11, Diciembre 2009

www.periferia.name

capacidad para que las mujeres complementen los ingresos de sus hogares ${ }^{3}$. Los técnicos agregan:

Entonces fue cuando nos imaginamos la organización del sistema como una fábrica a cielo abierto, configurada como una cadena de valor cuya unidad se basa en la recreación de un pacto social que tiene como principal valor la palabra y que se manifiesta en el cumplimiento de los compromisos productivos, comerciales y financieros. ${ }^{4}$

En este sentido, el nombre "De manos y de palabras" intenta expresar aquello que, también según las hilanderas, los une, a saber: la cooperación, el trabajo artesanal, la relación de ayuda mutua y el compromiso basado en la palabra.

Cada eslabón de la cadena se integra sobre corredores viales en una comarca de seis poblados vecinos con un sistema financiero propio basado en un "pacto social voluntario". De este modo, los participantes lograron incrementar la renta y mejorar la distribución y el precio de la lana local, como así también, el valor de la hora de trabajo; crearon un sistema de precios justos, idearon productos y mercados y una garantía solidaria en las transacciones, pactadas por medio de la palabra. La cadena incluye productores primarios, hilanderos, tejedores, comercializadores y técnicos que responden a un "nuevo patrón de comportamiento" ${ }^{5}$.

Las cadenas están organizadas en tres ejes denominados "bancos"6:

- Banco de Insumos Estratégicos: se conformó a través de la Fundación Saber Cómo con un monto inicial de $\$ 5000$ ayudando al establecimiento de un sistema financiero estructurado en bancos comunitarios de la lana articulados. Así, se logró organizar a productores ovinos para la mejora de a fibra de lana con la cual se abastecen los artesanos textiles.

\footnotetext{
3 Comentario extraído del artículo "Perfiles de las mujeres que hilaron su historia", Diario La Nación, sábado 26 de agosto de 2006, Sección Economía Social.

${ }^{4}$ I bíd. anterior.

${ }^{5}$ Ibíd. anterior.

${ }^{6}$ Extraído del Noticiero Tecnológico Semanal № 56, 4 de junio de 2007, INTI [www.inti.gob.ar]
} 


\section{perifèria}

Número 11, Diciembre 2009

\section{www.periferia.name}

- Banco de Diseño y Asistencia Técnica: una de las innovaciones tecnológicas de mayor impacto en la cadena lo constituye el uso de una rueca modificada por el INTI, que hace más productivo el tiempo de hilatura y posibilita la diversificación de tipologías de hilos a producir. Para la fabricación de la rueca, se capacitó y gestionó el armado de un taller de carpintería que genera trabajo para jóvenes judicializados del Hogar Taller "Sierra Dorada" (San Marcos Sierra). Tanto los ciclos de capacitación diseñados en relación con las necesidades de los distintos eslabones de la cadena, como la asistencia técnica continua, buscan la profesionalización de los distintos eslabones.

- Banco del Agente Comercial: se realizó la profesionalización de un grupo de negocios promotores para la venta de los productos, mediante la introducción de tablas de costeo, organización de los productos en colecciones para la mejor tracción de ventas y el manejo de herramientas de marketing y administrativas.

A partir de lo mencionado hasta el momento, podemos hallar varios aspectos a considerar, a saber: las características de los procesos de trabajo y el concepto de trabajo, la relación entre unidades domésticas y mercado formal, la relación entre Estado y sociedad civil, entre otros. Resulta importante tener en cuenta que la profundización de la crisis socioeconómica durante la década del ' 90 , ha revitalizado los postulados de la economía social, dando lugar a distintos tipos de emprendimientos sociales y cooperativos que intentan construir proyectos de vida colectivos que permitan abrir nuevos senderos frente a la crisis. Por consiguiente, es necesario abordar la problemática que surge de estas iniciativas no sólo en sus aspectos socioculturales, sino también, ahondando en sus aspectos económicos, políticos e ideológicos, los cuales confieren un carácter complejo y multidimensional al fenómeno. En este sentido, en primer lugar, nos proponemos analizar, en este artículo, las formas de extensión del modelo de organización empresarial hacia los emprendimientos de la economía social (en nuestro caso, una cadena productiva textil) y, en segundo lugar, la noción de "precio justo" y la coexistencia de dos mercados, a saber, aquel propiciado por el "comercio justo" y el mercado formal, 


\section{perifèria}

Número 11, Diciembre 2009

\section{www. periferia. name}

en los cuales participan los integrantes de dicho emprendimiento. Para dar cuenta de la relación planteada en el primer punto, hemos elegido analizar el documento “Tejiendo redes" del CIPPEC (Centro de Implementación de Políticas Públicas para la Equidad y el Crecimiento), tomándolo con un claro ejemplo del discurso hegemónico sobre la organización de la economía social.

\section{Extensión de las formas capitalistas de organización del trabajo hacia la sociedad civil y formas de subjetividad}

En los años '50, la emblemática empresa Toyota comenzó a implementar el denominado Kan-ban o "Just in time", a partir del cual pudo responder a la demanda sin aumentar su personal. Aquí, la fabricación no se realiza "en cadena" (de arriba hacia abajo) sino que se parte de los pedidos dirigidos a la fábrica y de los productos vendidos (de abajo hacia arriba).

En el marco de un cambio importante en las formas de organización del trabajo, se incorporan las tareas de control de calidad a los puestos de fabricación. En este sentido, los trabajadores deben poder resolver cualquier problema que surja en el proceso de producción. De este modo, la creatividad, la capacidad reflexiva, el compromiso, la responsabilidad y mayor autonomía de los trabajadores son aspectos fuertemente alentados por la empresa.

La nueva gestión del trabajo se sostiene, a la vez, sobre la producción de un saber técnico y un saber ser (Figari 2003:108). En el marco de este sistema de

\footnotetext{
${ }^{7}$ Según datos de la página Web (www.cippec.org.ar), se trata de una organización independiente y sin fines de lucro que trabaja por "un Estado justo, democrático y eficiente que mejore la vida de las personas". Para ello concentra sus esfuerzos en analizar y promover políticas públicas que fomenten la equidad y el crecimiento en la Argentina. Su desafío es traducir en acciones concretas las mejores ideas que surjan en las áreas de Desarrollo Social, Desarrollo Económico y Fortalecimiento de las Instituciones, a través de los programas de Educación, Salud, Política Fiscal, Inserción Internacional, Justicia, Transparencia, Instituciones Democráticas, Desarrollo Local, Política y Gestión de Gobierno e Incidencia de la Sociedad Civil. EI CIPPEC trabaja conjuntamente con la Subsecretaría para la Reforma Institucional y Fortalecimiento de la Democracia de la Jefatura de Gabinete de Ministros de Presidencia de la Nación Argentina, con el Ministerio de Desarrollo Social de la Nación, el cual asimismo se vincula con el INTI en Capilla del Monte, Córdoba. El CIPPEC posee el apoyo del Banco Mundial, Banco Interamericano de Desarrollo, Comisión Económica para América Latina y el Caribe (CEPAL) y un número importante de empresas transnacionales. Cabe mencionar, a propósito de nuestro trabajo, que el CIPPEC realiza trabajos de consultoría con la Municipalidad de Capilla del Monte, Córdoba.
} 


\section{perifèria}

Número 11, Diciembre 2009

www.periferia.name

producción, los trabajadores ya no serán considerados como un apéndice de la máquina desprovisto de capacidad de resolución y pensamiento sino que, ahora, los trabajadores serán incitados a aportar opiniones, participar en discusiones sobre la toma de decisiones en torno a la organización del trabajo y a usar su creatividad para solucionar problemas (Rosendo 1998; Castillo 1988; Neffa 1999).

En este sentido, la reestructuración del modelo de producción implica transformaciones en aspectos como: 1) Priorizar la distribución de tareas en pequeños grupos de trabajo, en lugar de los puestos individuales y las actividades parcializadas, mecánicas y repetitivas; de esta forma se incorporan técnicas de control más sofisticadas: el control no se da únicamente de forma externa, es decir, desde la gerencia (supervisores, capataces) sino también entre los propios trabajadores garantizando de esta forma el cumplimiento de las políticas empresariales. 2) Instaurar una nueva organización del trabajo que responda a una producción "flexible", en función de la demanda y ya no en la lógica de producción basada en la línea de montaje y la producción seriada. En este sentido, se requiere que el trabajador pueda cumplir múltiples funciones 3 ) Incorporar cambios a nivel de la organización del trabajo, de innovaciones organizacionales, y no tanto de incorporación de tecnología, aunque evidentemente también son muy importantes. El reto para el capital es la creación de una nueva "cultura laboral" que comprometa a los trabajadores con los objetivos de productividad que hoy imperan en el mercado. De este modo, se torna interesante analizar la reconformación de las estructuras de poder y autoridad al interior de las unidades productivas, donde se tendrán que construir nuevas formas de disciplinamiento (nuevos estilos de liderazgo, co-participación, etc.) que promuevan el incremento de productividad.

La idea de trabajador-patrón y la creciente disolución de la separación entre trabajo de concepción y trabajo de ejecución, derivan en lo que consideramos una ética del autodisciplinamiento, la cual implica también formas de autoexplotación. La relación dialéctica entre la racionalidad del capitalista y la racionalidad del trabajador plantea, pues, una paradoja. Es decir, los trabajadores son condicionados para pensar y actuar como si fuesen "capitalistas" y exigirse el máximo, no sólo a sí mismos sino también a los demás, pues el "éxito" o el "fracaso" de la empresa se

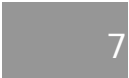




\section{perifèria}

Número 11, Diciembre 2009

\section{www.periferia.name}

encuentran en sus manos. De este modo, el trabajador no se siente explotado ya que se le ofrece la posibilidad de ser su propio patrón, de dirigir su trabajo (Aubert y De Gaulejac 1993). Aunque, es más que probable que no ocurra del mismo modo en todos los casos. Sin embargo, todo lo antedicho facilita la aceptación de las actuales formas de organización del trabajo y, por ende, contribuye a generar mayores ganancias para el capital.

Siendo, probablemente, en la actualidad, el potencial subjetivo de los trabajadores el principal aspecto en la acumulación de capital; la cooperación no se presenta sólo como algo necesario, propio y natural al proceso de trabajo. Esto quiere decir que la cooperación se constituye como una forma particular de poder que se ejerce con el propósito de crear nuevos comportamientos que estimulan las capacidades intelectuales de los trabajadores. Sin embargo, no se trata de un poder que cae sobre los trabajadores sino que cada trabajador, sin importar su posición, construye, ejerce y conserva ese poder y, al mismo tiempo, agudiza su propia alienación. La ideología empresarial engendra ficciones pero estas ficciones no son impuestas desde exterior sino que, en general, son producidas y reproducidas por los mismos trabajadores en un juego constante de relaciones de poder.

Surge una racionalidad distinta donde la toma de decisiones y la resolución de problemas, más allá de basarse sobre cifras y lógicas, se orientan a los elementos subjetivos y afectivos, los cuales se adaptan mejor a los fines que persigue la empresa. Por tanto, la concepción de un trabajador flexible aparece como la síntesis del actual proceso de trabajo y, a la vez, reformula el significado que adquiere el trabajo para los sujetos.

Ahora bien, lo mencionado hasta ahora, podemos también hallarlo en la organización de la cadena productiva ${ }^{8}$ considerada en el marco de la economía social y el comercio justo. Durante nuestro trabajo de campo, pudimos dar cuenta que, en la misma, se produce una extensión de las formas de organización de los

\footnotetext{
${ }^{8}$ Una cadena productiva o cadena de valor integra lo que se conoce como circuito productivo, el cual abarca un conjunto de unidades de producción, distribución y consumo que operan intervinculadas entre sí a partir de una actividad común a todas ellas (Rofman 1999: 35)
} 


\section{perifèria}

Número 11, Diciembre 2009

www.periferia.name

procesos de trabajo capitalistas conocidos como "postfordistas", aunque también en estos aparecen elementos característicos de las etapas "tayloristas-fordistas".

Los monitoreos constantes de los técnicos del INTI sobre los procesos de trabajo realizados por las unidades domésticas se sustentan no sólo en procurar la "eficiencia y productividad" de las trabajadoras (puesto que se trata, en su mayoría, de mujeres) sino que, también, se fundamenta sobre el postulado de que “la libertad es necesaria pero también es necesario condicionarla o limitarla para que se continúen cumpliendo los compromisos", según palabras del funcionario del INTI, creador y "líder" del proyecto. Esto último, se lleva a cabo a través de los protocolos, los cuales se elaboran sobre la base de un proceso de "estandarización" de los saberes de las trabajadoras y trabajadores. Al respecto, veamos la siguiente explicación sobre el funcionamiento de la cadena productiva:

Toda la organización tiene protocolos, toda transacción de eslabón, no de personas, de eslabón, los que tejen con los que hilan. Cada vez que hay una transacción hay un protocolo de la transacción, ese protocolo lo que hace es que el que entrega el bien y el que toma el bien están ajustados, el bien que se entrega y el bien que se toma están ajustados, de tal forma que haya la mayor transferencia de valor. Cómo te puedo explicar. Si tú tienes un bien que no está ajustado con el del otro, el otro pierde tiempo en ajustarlo antes de ingresarlo netamente en el proceso de transformación. Entonces este protocolo ajusta. (Testimonio funcionario INTI 2009)

Asimismo, en documentos facilitados por funcionarios de la institución, encontramos que, desde el punto de vista micro, se sostiene que la generación y circulación de conocimientos al interior de las unidades productivas constituye un proceso complejo cuya intensidad depende:

- De la necesidad de resolver problemas concretos en situación de incertidumbre, lo que estimula la demanda de soluciones no codificadas;

- Del grado de complejidad técnica de los equipos de trabajo;

- Del tipo de competencias básicas de los agentes;

- De la capacidad de relacionarse y de trabajar en forma grupal y del grado de 


\section{perifèria}

Número 11, Diciembre 2009

www.periferia.name

aprovechamiento de los saberes técnicos y organizacionales de los trabajadores.

Ahora bien, podemos observar que los puntos precedentes concuerdan la racionalidad del modelo empresarial de organización del trabajo. Precisamente, esta práctica se inscribe en la política pública del gobierno nacional, del cual depende el INTI, de "disminución de la pobreza por medio de la inclusión productiva". En este sentido, el emprendimiento se encuentra ligado al concepto de desarrollo, el cual históricamente se vincula con el economicismo y el eurocentrismo. Retomando a Viola Recasens (2000), el primero se funda en la centralidad de la teoría económica neoclásica en la configuración de las imágenes dominantes del desarrollo, como por ejemplo, la identificación del desarrollo con el crecimiento económico y con la extensión de una economía de mercado globalizada. El segundo, refiere a la aplicación de un modelo occidental de sociedad como parámetro universal para medir el relativo progreso o atraso de los pueblos. De este modo, se combinan un fuerte positivismo (creencia en que los valores y hechos pueden ser separados nítidamente) y un pensamiento evolucionista (la idea de estadios de desarrollo progresivos a partir de los cuales los pueblos "atrasados" avanzarán hasta el ideal de sociedad universalmente válido y deseable). Así, el concepto de desarrollo plantea la unicidad, homogeneidad y unilinealidad evolutiva del mundo, presentándose como única vía de escape de una condición, considerada indigna, llamada subdesarrollo (Esteva 2000: 70 y 77).

De esta manera, la pobreza pierde su carácter esencialmente político (inseparable de una desigual correlación local y global de fuerzas), para convertirse en un problema técnico, de asignación de recursos, o de "deficiencias" nutritivas, educativas y sanitarias de un sector de la población.

(Viola Recasens 2000: 21)

En su estudio sobre la racionalidad económica, Godelier (1974) advierte que, en torno a la noción de racionalidad económica en el marco de la economía política, aparecen otras palabras como eficacia, eficiencia, rentabilidad, rendimiento, productividad, minimización de costos, utilidad máxima, satisfacción máxima, 


\section{perifèria}

Número 11, Diciembre 2009

www. periferia. name

decisión óptima, elección, cálculo, previsión, gestión organizada del trabajo, desarrollo, crecimiento equilibrado, progreso, justicia, etc. Siendo, en este sentido, la falta de espíritu de empresa la raíz de la miseria y el "subdesarrollo", entonces, lo anterior refiere a la racionalidad específica del empresario o capitalista, la cual se postula como única posible. De modo tal que la racionalidad aparece como un dato invariable de la naturaleza humana, como un hecho cotidiano y banal de la experiencia que refiere a un "a priori" no histórico o transhistórico. Para la economía política clásica y los marginalistas, la racionalidad presupone a un individuo con necesidades ilimitadas que, en un contexto de recursos escasos, se comporta previsiblemente asignando dichos recursos a fines alternativos. Este modelo basado en el empresario capitalista se extiende a todos los sujetos sociales con el propósito de conformarlos como sujetos económicos (el trabajador, el consumidor, etc.). En nuestro caso, se trata de la construcción de un sujeto "emprendedor".

Los testimonios de las trabajadoras, obtenidos en observaciones y entrevistas, resaltan la "dignidad del trabajo en casa" por tratarse de un "trabajo noble" que, además, puede insertarse en el mercado, el cual permite la "inclusión para personas sin alternativas de empleo". Durante nuestras observaciones en el campo, hallamos un fuerte control y autocontrol de los tiempos de producción, internalizados por las propias trabajadoras, lo cual constituye una parte relevante de las estrategias de disciplinamiento.

Yo parto de una sociedad que está fracturada, en realidad la llamé fragmentada, conceptualicé que es fragmentación social y dije que fragmentación social no es división social. Que la división social es un proceso donde las células, la sociedad se divide en células y el límite es el individuo, pero la fragmentación divide al individuo, es la división del individuo porque lo divide moralmente, dice una cosa... Esto tiene que ser un proceso fuertemente reconstructor de una ética y una moral, fuerte. Por otro lado yo postulaba que, como hipótesis de trabajo, que un sistema, moral y éticamente, más fuerte disminuye sus costos efectivos, en términos económicos. (Testimonio funcionario INTI 2009) 


\section{perifèria}

Número 11, Diciembre 2009

www.periferia.name

De esta forma, consideramos que el aspecto central sobre el cual se construye dicha disciplina remite a la redefinición de las relaciones sociales en términos afectivos, ya no de clase. El ejercicio del poder opera a partir de un saber minucioso en torno a las distintas problemáticas de índole afectiva que atraviesan a cada uno de los sujetos involucrados. El control de posibles conflictos sociales latentes queda asegurado en la interpelación ético-moral que conlleva esta forma de autodisplinamiento. Es decir, la solidaridad y ayuda mutua no hacen más que resaltar carencias sociales, afectivas y económicas, que son instrumentalizadas para generar formas de subordinación de la fuerza de trabajo a la lógica del mercado.

Resulta interesante notar que en el documento "Tejiendo redes" del CIPPEC, se plantea una debilidad de las organizaciones de la sociedad civil (OSC), a saber, el cuestionamiento del poder y la autoridad cuando se hallan más allá del EstadoNación. En el marco de su propuesta de un "gobierno transnacional" son necesarias aquellas redes que articulan y conectan las OSC con el sector público y privado, resaltando para este fin, la importancia de la información, la sinergia y la cooperación. Se sostiene, asimismo, que las “organizaciones del sector público y de la sociedad civil están mirando con curiosidad las experiencias del sector privado como una parte integral de la eficiencia institucional".

A este planteo, podemos agregar unos de los conceptos clave del INTI: la solidaridad tecnológica. Este último, implica que los excluidos deben ser integrados a la producción. Los ciudadanos deben producir al menos lo que consumen. En este sentido, enfatiza en la importancia del trabajo como elemento de integración y en la gestión del saber cómo (conocimientos). La solidaridad tecnológica conlleva la transferencia de conocimientos para una vida más autónoma. Supone una estrategia de liberación respecto del monopolio del saber en manos de corporaciones transnacionales para el logro de un desarrollo autónomo.

Según Foucault (2008), la regulación del poder público en términos de utilidad se impone a la axiomática de la soberanía en términos de derechos originarios. La utilidad colectiva (más que la voluntad colectiva) constituye el eje principal del arte de gobernar. En este sentido, se constituye un nuevo pacto social en el cual el 


\section{perifèria}

Número 11, Diciembre 2009

\section{www.periferia.name}

sujeto interpelante que funda la escisión entre lo público y lo privado ya no es el Estado nacional, sino los organismos internacionales (Murillo 2008). De este modo, el sector público habilita, coordina, organiza y encauza el potencial social (habilidades y capacidades de trabajo) hacia el mercado. Ahora bien, Foucault sostiene que el gobierno estatal debe intervenir sobre la población en el plano de las técnicas, poniendo a disposición de la gente una serie de herramientas, perfeccionando técnicamente diferentes elementos, formación de los trabajadores y la enseñanza que se les imparta. Esto último, tiene como propósito que determinados procesos de trabajo, en nuestro caso, ligados al trabajo doméstico artesanal, puedan funcionar como un mercado y en el mercado.

En el neoliberalismo, la política social, atravesadas por la noción de desarrollo económico, implica lo siguiente:

Se trata simplemente de garantizar, no el mantenimiento de un poder adquisitivo, sino un mínimo vital en beneficio de quienes, de modo definitivo y no pasajero, no puedan asegurar su propia existencia (Foucault 2008: 177)

Al analizar nuestro caso en contexto político-económico más amplio, podemos hablar del ejercicio de un arte de gobierno indirecto ${ }^{9}$. Es indirecto puesto que requiere de la mediación, especialmente, de las instituciones estatales para efectivizar la puesta en práctica de las políticas de desarrollo, las cuales constituyen uno de los ejes centrales de las transformaciones en la dinámica de acumulación del capital. Países como el nuestro, endeudados y subordinados económicamente con organismos de crédito internacionales, se hallan alineados a sus postulados, incorporan, habilitan y legitiman su poder.

\footnotetext{
9 "El arte de gobierno debe fijar entonces sus reglas y racionalizar sus maneras de obrar, proponiéndose en cierto modo como objetivo transformar en ser el deber ser del Estado" (Foucault 2008: 19) El arte de gobierno refiere a la dirección de conductas. Sin embargo, para nuestros propósitos, es necesario tener en cuenta que gobierno y Estado no son lo mismo. Así, el "gobierno" no refiere únicamente a estructuras políticas o a la dirección de los estados pues, ante todo, designa el "arte" según el cual podría dirigirse la conducta de los individuos o de los grupos. Existe una diferencia entre Estado y gobierno, puesto que implican distintos agentes para su ejecución.
} 


\section{perifèria}

Número 11, Diciembre 2009

www. periferia. name

En el discurso de los organismos internacionales se habla de un "nuevo pacto social" establecido por la concordancia de los intereses de los distintos sectores de la sociedad. Sin embargo, consideramos que con este "nuevo pacto social", los organismos internacionales interpelan a la sociedad civil con el fin de crear una obligación a partir de la cual los sujetos reconozcan su poder. Aquí, la utilidad social adquiere un sentido dado por la preeminencia de la maximización de beneficios económicos. Esta idea de pacto surge con la excusa de la "corrupción" de los actuales gobiernos y sus instituciones, lo cual implica la necesidad de reforma de las mismas. Dicha reforma, a su vez, requiere del reconocimiento de la legitimidad de las prácticas de los organismos internacionales para su implementación. El arte de gobierno indirecto se despliega a través de distintas estrategias que cuentan con la mediación de distintos agentes (gubernamentales, privados y/o no gubernamentales, según sea el caso) los cuales garantizan la viabilidad de sus intereses y la rentabilidad de sus inversiones. Estas estrategias confluyen en una misma dirección: la incorporación de los llamados "sectores vulnerables" al mercado. Organismos de crédito internacional, exigen un marco legal que proteja la propiedad privada (garantizado por el Estado) e invocan los derechos individuales. Ofrecen la esperanza de mayor libertad e igualdad, paradójicamente, a través del miedo a su pérdida absoluta. Agreguemos a esto, seguridad y propiedad privada, en fin, la perpetuación y naturalización de la desigualdad. Azuzados por el miedo de un mal (pérdida de la fuente de trabajo, incertidumbre, falta de valoración social), han hallado en ese Otro (Estado y organismos internacionales) la esperanza de un beneficio. $Y$ es este miedo y esta esperanza los que unen a los sujetos, que son interpelados en tanto "emprendedores" $y$, en cuyas manos pero con la guía apropiada, se encuentra toda posibilidad de mantener dicha esperanza. Miedo y esperanza van de la mano. Las relaciones de poder y la disciplina se edifican sobre estos cimientos, abonados por las constantes crisis y reestructuraciones de la dinámica del sistema económico capitalista.

Precisamente, Quijano (2000) plantea la constitución de un Bloque Imperial Mundial (integrado por los modernos estados-nación del "centro" del sistema mundial y entidades intergubernamentales y privadas como el Banco Mundial, el 


\section{perifèria}

Número 11, Diciembre 2009

www.periferia. name

Fondo Monetario Internacional, el Club de París y el banco Interamericano de Desarrollo, entre las principales) y la des-democratización y des-nacionalización de los estados dependientes y su conversión progresiva en agencias políticoadministrativas del capital financiero mundial y del bloque imperial mundial, lo cual expresa la re-concentración del control mundial de la autoridad pública y la reprivatización local de ésta.

Lo que el término democracia mienta en el mundo actual, en el patrón mundial de poder colonial/moderno/capitalista/eurocéntrico, es un fenómeno concreto y específico: un sistema de negociación institucionalizada de los límites, de las condiciones y de las modalidades de explotación y de dominación, cuya figura institucional emblemática es la ciudadanía y cuyo marco institucional es el moderno estado-nación. (Quijano 2000: 16)

Resulta notoria la relación que podemos hallar entre este arte de gobierno indirecto, con las viejas prácticas del gobierno indirecto colonial. Justamente, este último, se destaca por un detallado conocimiento de los aspectos socioculturales para afinar los mecanismos biopolíticos, un gobierno descentralizado, la necesidad de líderes comunitarios (en muchos casos, funcionarios estatales), la movilización de la fuerza de trabajo, las ideas de progreso y desarrollo y prácticas de patrocinio. En definitiva, "viejas prácticas colonialistas" se visten con nuevos ropajes adornados con lemas "democráticos". Por consiguiente, la práctica propuesta de un "gobierno transnacional" no puede más que invitarnos a la reflexión crítica acerca de su vigencia.

\section{"Comercio justo" y "precio justo": mercado de jurisdicción y mercado de veridicción.}

Según Foucault (2008), el mercado en el Medioevo y en los siglos XVI y XVIII, se definía como un lugar de justicia en cuanto contaba con una estricta reglamentación respecto de los objetos que debían llevarse al mercado, al tipo de fabricación de esos objetos, al origen de los productos, a los derechos que había que pagar, a los procedimientos mismos de la venta y a los precios fijados. 


\section{perifèria}

Número 11, Diciembre 2009

\section{www.periferia.name}

Precisamente, el precio de venta era un precio justo o debía serlo, ya que las transacciones se basaban en un ideal de moderación (ganancia moderada) y la ausencia de fraude. El mercado era un ámbito de justicia distributiva (especialmente de productos alimenticios) para los más pobres. De este modo, la masa del pueblo no sufriría de modo exagerado la miseria. En pocas palabras, el mercado para esta época constituía un sistema basado en una fuerte reglamentación, el precio justo y la sanción al fraude.

Santo Tomás de Aquino, sostiene que según ley divina se considera ilícito si en la compraventa no se observa la igualdad de la justicia. A veces, el justo precio ${ }^{10}$ de las cosas no está exactamente determinado (estimación aproximada). Un ligero aumento o disminución del mismo, al parecer, no destruiría la igualdad de la justicia. Según Santo Tomás, el precio de las cosas está determinado según la utilidad que los hombres tienen de ellas ${ }^{11}$. El lucro no implica por esencia nada vicioso o contrario a la virtud. Nada impide que ese lucro sea ordenado a un fin necesario o incluso honesto.

A mediados del siglo XVIII, el mercado se convierte en un lugar de verdad. Los precios, en cuanto se ajustan a los mecanismos "naturales" del mercado, van a construir un patrón de verdad que permitirá discernir en las prácticas gubernamentales, las que son correctas y las que son erróneas (Foucault 2008).

En nuestro caso, hallamos una "revitalización" de los postulados pertenecientes al mercado del Medioevo, los cuales se plasman en la existencia del denominado "mercado solidario o social" construido en el marco del comercio justo.

\footnotetext{
10 Aristóteles (1996) en la "Constitución de los atenienses", describe a los "inspectores de mercado" encargados de cuidar de todas las mercancías, de que se vendan puras y sin falsificación; "inspectores de medidas" encargados de cuidar de todas las medidas y pesos, para que los vendedores los usen justos; y "vigilantes del trigo" quienes inspeccionaban el mercado del grano y la venta de la harina y el pan, cuidan que el grano se venda a su precio justo.

${ }^{11}$ Esta noción de utilidad prevalece en la economía política clásica. Para Marx (1999), la utilidad es un atributo de la mercancía. El valor de uso posee ciertas propiedades, por ende, la mercancía es un valor de uso. Contrariamente, para Ricardo, el valor de uso está dado por la utilidad (es algo extrínseco a la cosa)
} 


\section{perifèria}

Número 11, Diciembre 2009

www.periferia.name

Precisamente, el comercio justo implica, según Cotera Fretell y Ortiz Roca (2004), la igualdad y el respeto mutuo, la certificación orgánica y la calidad de los productos producidos. Según dichos autores, el comercio justo opera a escala local y regional en una perspectiva de desarrollo integrado $y$, por supuesto, se vincula a la economía social y solidaria. Asimismo, plantean la multifuncionalidad del comercio justo en términos de estrategia de comercialización, promoción local sostenible y sustentable, generación de empleo, relaciones de equidad, movilización de valores ético culturales, desarrollo desde el espacio local. Esto último, requiere del diálogo entre el Estado, las multilaterales y las redes sociales, enfatizando en el reconocimiento del Estado que ha de expresarse en leyes que normen y promuevan la responsabilidad social y ambiental de la actividad productiva y comercial. Aquí, se manifiesta aquello que planteábamos en la sección anterior, es decir, la construcción de un "arte de gobierno indirecto" que apunta a la incorporación de los denominados "pobres" al mercado. Justamente, la coexistencia de un mercado de justicia y un mercado de verdad y la doble participación de los sujetos en los mismos, constituye el fundamento de esta forma que adquiere la tecnología de gobierno. Su propósito no es meramente económico, sino fundamentalmente sociocultural, es decir, se vincula con una reconfiguración de las subjetividades y las percepciones en torno al trabajo humano. El sistema capitalista arroja enormes cantidades de trabajadores fuera de los espacios formales de producción, sin embargo, los reincorpora en tanto productores/consumidores a través de los emprendimientos productivos de la economía social y solidaria, asegurando la continuidad del mercado. La coexistencia que antes mencionábamos de ambos mercados no representa una alternativa o compensación frente a las inclemencias de la economía capitalista, sino una transformación en la dinámica de acumulación del capital la cual, históricamente, ha operado subordinando nuevos procesos de trabajo bajo su órbita.

En un sentido paradójico, las unidades domésticas que conforman la cadena productiva textil, desarrollan estrategias cuyo objetivo será intentar salir de su posición, a partir de una pluralidad de bases económicas (Comas D' Argemir 1998). En las mismas, podemos encontrar la articulación de diferentes formas de 


\section{perifèria}

Número 11, Diciembre 2009

\section{www.periferia.name}

producción sin dejar de reconocer que la lógica capitalista se impone en sus prácticas. De este modo, surge una nueva paradoja: la lógica que las excluye es la misma que los sujetos, a su vez, ponen en práctica para insertarse nuevamente en el mercado. Esta relación, al interior de las unidades domésticas, se manifiesta en la dialéctica totalidad - fragmentación. La fragmentación a partir de la pluralidad de bases económicas implica una segunda relación dialéctica entre la unidad doméstica y el sistema capitalista. Si bien, cada miembro se encuentra vinculado a relaciones laborales diferentes, el objetivo que sigue la unidad será persistir como una totalidad.

En el caso analizado, observamos que en los sujetos prevalece este deseo de permanecer en el sistema capitalista como una forma no sólo de autosubsistencia sino también de valoración social. De este modo, encontramos tanto relaciones sociales como relaciones de producción contradictorias. Ahora bien, esto implica que las distintas variantes con las cuales se manifiesta la racionalidad de la organización socioeconómica de las unidades domésticas, se halla siempre subordinada a las exigencias de la racionalidad empresaria (capitalista) que el mercado formal demanda en términos de requisito ineludible para permanecer en el mismo.

La lógica económica es contraria a la intuición, requiere recortes artificiales que permitan predecir y calcular el futuro (Foucault 2008). En el marco del neoliberalismo, la competencia aparece como posibilidad de libertad (por supuesto, limitada). El porvenir deja de ser una intuición para convertirse en un cálculo de posibilidades. La independencia de los sujetos queda asociada a la mera condición de consumidores / competidores en el mercado. A dicha libertad como tecnología de poder, se suma la esperanza.

Yo, mira, cuando hice esto, si bien tenía una clara vocación de servicio, yo trabajo con personas de las cuales les conozco el nombre, el apellido, su intimidad, su vida y soy amigo, me quieren, pero lo hice por un profundo interés de dejar mi aporte en quién quiera de una visión distinta de cómo hacer la intervención pública o la intervención privada. Yo siempre me situé desde un agente del estado. (Testimonio funcionario INTI 2009) 


\section{perifèria}

Número 11, Diciembre 2009

www.periferia.name

A partir de testimonio precedente, podemos observar el modo en que, al conocer profundamente los anhelos y afectos de los trabajadores/as involucrados, se edifican los cimientos de la intervención pública y/o privada. Precisamente, frente a las constantes crisis socioeconómicas y sus consecuencias "fragmentadoras" de lo social y cultural, este tipo de intervención debe concentrar nuevas posibilidades, nuevas esperanzas.

La puesta en práctica de la colonización de la esperanza termina por convertirla en un aspecto colonizador de voluntades y afectos. Así, esta se torna en un aspecto central en la construcción de poder. En relación a esto, resulta interesante pensar, retomando a Esteva (2000), que el desarrollo alude a la colonización económica de lo que se ha llamado sector informal. En este contexto, según el autor, las actividades autónomas de los sujetos, las cuales representan deseos, capacidades y esperanzas, se transforman en una serie de necesidades cuya satisfacción requiere de la mediación del mercado.

Los sujetos tienen esperanza porque esperan. Esperan algo que no se halla en ellos mismos. La esperanza implica la creencia (fe) en que Otro permitirá que se logre lo deseado. Aquellos que viven esperanzados, viven sólo en el porvenir. El pasado se encuentra reservado a lo no deseado, a aquello de lo cual se desea escapar, superar, olvidar. El presente, destalla en instantes que tornan manifiesta la espera. El instante es vivido sólo cuando aporta una novedad que reafirma la esperanza y, así, refuerza con nuevos indicios la necesidad de esperar. Si bien, la esperanza aporta fuerzas creadoras, también genera una inmensa capacidad de distorsión, pues el engaño y el autoengaño son sus aliados. La esperanza no hace más que proyectar su sombra para lograr que se aferren a ella. Es el miedo a la muerte (en todos los sentidos posibles) su sombra y su instrumento para subyugarlos a ese Otro (en nuestro caso, el Estado y sus instituciones) en el cual es depositada. Esperanza y promesa de salvación van de la mano y, tras ellas, camina el miedo a paso firme. En la espera, el tiempo se desvanece, sólo se intuye el porvenir. La intuición de ese porvenir redentor, despojado de todo miedo, los envuelve en un sentimiento de libertad. Libertad, que los esperanzados alcanzan en la medida en que sus actos satisfacen el mandato de ese Otro, fuera de ellos 


\section{perifèria}

Número 11, Diciembre 2009

www.periferia.name

mismos y cuyo favor desean. Así, miedo y libertad, en apariencia contrarios, coexisten en la esperanza. En la espera que implica esta última, se manifiesta el poder de ese Otro y la negación su propia autodeterminación.

\section{Reflexiones finales}

Las paradojas y complejas relaciones que plantea la economía social, en la cual se enmarca el comercio justo, nos conduce a sostener que, difícilmente, pueden estas iniciativas considerarse en términos de "alternativas" en oposición a la economía capitalista. Tanto la extensión del modelo empresarial como sus formas de disciplinamiento nos permiten observar una reconfiguración de las subjetividades de las unidades domésticas y sus integrantes. En este sentido, planteamos las implicancias de lo que denominamos colonización de la esperanza, sobre la cual se cimienta la construcción de formas de poder y dominación de la fuerza de trabajo.

Las relaciones entre el Estado, organismos internacionales y sociedad civil, propicia modos específicos de ejercicio del poder que nos permiten pensar en una actualización y re-semantización de "viejas" prácticas coloniales de gobierno amparadas bajo políticas de desarrollo local.

Lo anterior no sólo responde a una transformación en la dinámica de acumulación del capital, la cual conlleva heterogéneos procesos de subsunción del trabajo al capital (Marx 1981), sino también, un esfuerzo descomunal por asfixiar la irrupción de conflictividades potenciales o existentes. Por supuesto, el presente artículo contiene aspectos que aún requieren una mayor profundización y análisis, sin embargo, ha sido nuestro propósito plantear aquellas cuestiones centrales que atañen a nuestro enfoque analítico.

\section{Bibliografía}

Aristóteles (1996). Constitución de los atenienses. España: Gredos.

Castillo, Juan José (1988). Las nuevas formas de organización del trabajo, en Castillo, J.J. (comp.) Las nuevas formas de organización del trabajo. Madrid: Centro de Publicaciones Ministerio de Trabajo y Seguridad Social. 


\section{perifèria}

Número 11, Diciembre 2009

www.periferia.name

Comas D’ Argemir, Dolors (1998). Antropología Económica. Barcelona: Ariel.

Cotera Fretell, Alfonso y Ortiz Roca, Humberto (2004) Comercio justo, en Cattani, David (org.) La otra economía. Buenos Aires: Altamira.

Esteva, Gustavo (2000). Desarrollo, en Viola, A. (comp.) Antropología del Desarrollo. Teorías y estudios etnográficos en América Latina. Barcelona: Paidós.

Figari, Claudia (2003). Lógicas de formación y de calidad en la modernización empresaria, en Revista Estudios del Trabajo, № 22, ASET, Bs. As.

Foucault, Michel (2008). El nacimiento de la biopolítica. Buenos Aires: FCE.

Godelier, Maurice (1974). Racionalidad e irracionalidad en economía. México, Siglo $\mathrm{XXI}$.

Landaburu, Liliana y Presta, Susana R. (2007). Elementos para la reflexión en torno al concepto de unidad doméstica en el contexto neoliberal. Revista Papeles de Trabajo № 14, Universidad Nacional de Rosario.

Marx, Karl (1981). Capítulo VI (ex-inédito). México: Siglo XXI.

Marx, Karl (1999). El Capital (Sección I, Tomo I). México: FCE.

Murillo, Susana (2008) Colonizar el dolor. La interpelación ideológica del Banco Mundial en América Latina. El caso argentino desde Blumberg a Cromañón. Buenos Aires: CLACSO.

Neffa, Juan Carlos (1999). Crisis y emergencia de Nuevos Modelos Productivos en De la Garza, E. (comp.) Los retos teóricos de los estudios del trabajo hacia el s. XXI. Buenos Aires: CLACSO.

Quijano, Aníbal (2000). Colonialidad del poder, globalización y democracia. Caracas-Venezuela: Instituto de Estudios Diplomáticos e Internacionales Pedro Gual.

Rofman, Alejandro (1999). Las economías regionales a fines del siglo XX. Buenos Aires: Ariel.

Rosendo, Ricardo (1998). Disciplinas y control social del trabajo en tiempos de la 


\section{perifèria}

Número 11, Diciembre 2009

www. periferia. name

producción posfordista, en Neufeld, M. R.- Grimberg, M.-Tiscornia, S.-Wallace, S. (Comp.) Antropología Social y Política. Hegemonía y poder: el mundo en movimiento. Buenos Aires: Eudeba.

Viola Recasens, Andreu (2000). La crisis del desarrollismo y el surgimiento de la antropología del desarrollo, en Viola, A. (Comp.) Antropología del desarrollo. Barcelona: Paidós. 